\title{
Unveiling and Revealing the Mirror: Mobile Reverberations in Patrick Bokanowski's Animated Films
}

animation:

an interdisciplinary journal

2019, Vol. 14(2) 83-101

(C) The Author(s) 2019

Article reuse guidelines:

sagepub.com/journals-permissions

DOI: 10.1 I77/I7468477|9856997

journals.sagepub.com/home/anm

$\Theta$ SAGE

\section{Tamara Rama and Carmen Lloret \\ Polytechnic University of Valencia, Spain}

\begin{abstract}
The principal focus of this article is to provide an analysis of some of the most significant works by the independent filmmaker Patrick Bokanowski and the methodology he uses to create those animated films. It addresses Bokanowski's technique of filming on various kinds of reflective surfaces as a strategy for transforming the image through optical deformation and thereby expressing his subjective vision in films and animation. He explores the practical application of creating reverberation as visual echoes, as well as the use of unusual reflections that appear in mirrors and other more unstable reflective surfaces, such as liquid mercury, and the refraction occurring in sculpted lenses, glass or water. The aim of this strategy is the pure expression of subjective experience, with the director using a camera as if it were an entirely free-moving paintbrush that inspires creativity and breaks loose from automatic camera movements. Accordingly, this study examines the dynamic, expressive potential of the language of catoptrics, taking as paradigmatic examples two of Bokanowski's short films: La Plage (1992) and Au bord du lac (1994). The authors' analyses of these films are aimed at demonstrating how the artist manages to bring about qualitative, transformative changes of forms and space by reflecting images on mirrors, ripples in mercury and movements of water, and by combining these elements. The system developed by Bokanowski successfully transports us to an ever-changing, poetic universe and breaks new ground in the field of animation.
\end{abstract}

\section{Keywords}

artistic animation, deformation, mirrors, moving expression, Patrick Bokanowski, reflected image, space-time, subjective vision

\section{Corresponding author:}

Tamara Rama, Department of Drawing at the Faculty of Fine Arts at the Polytechnic University of Valencia (Universitat Politècnica de València), Camino de Vera, s/n, 46022 Valencia, Spain.

Email: taraso@bbaa.upv.es 


\section{Introduction}

The main intention of this article is to examine the way in which independent filmmaker and animator Patrick Bokanowski manages to express his subjective vision of space to re-create an imaginary world. ${ }^{1}$ He does so by combining animation with a distortion of reality in mirrors as well as various other kinds of reflective surfaces. The analysis focuses on Bokanowski's methodology and a number of his animated films, which do not fall under the standard technical definition of animation. His alternative methods foster a freedom in creative artistic processes and connect his auteuranimation practices with other disciplines such as drawing, painting and performance art. Thus, a key aim of this article is to demonstrate the wealth and extraordinary diversity of approaches and methods in contemporary animation, which is undergoing a continuous renewal of its graphic and cinematic languages, and ultimately to generate other ways of creatively re-imagining animation, in terms of both form and content. As Paul Wells affirms in Understanding Animation (1998):

It seems necessary to reclaim, re-introduce and re-validate animation with other materials, with different creative impulses and aesthetic interests, outside the context of mass production, to properly evaluate the achievements of the animated film. It also provides an opportunity to theorise the textual apparatus of different forms of animation. (p. 35)

Wells' assessment highlights the importance of re-thinking animation and looking further afield in regard to both aesthetic and ideological issues, in search of new possibilities that could reveal heterogeneous new ways of considering animated film while eschewing formal and theoretical conventions. The desired result is a richer, broader and more up-to-date perception of animation - a perception which is more open and integrates different angles that encourage other readings and other contemporary, less orthodox, hybrid viewpoints, without systematically aligning with the hegemonic standard approach.

This is the case with Bokanowski, whose filmography is based on non-orthodox animation and originates from an individual perception that lies outside the predominant trends of mainstream filmmaking. Right from the beginning, his film work has been linked to animation. He describes it as follows:

I learned filmmaking with a friend, an animator called Jean Mutchler. So right from the start I wasn't filming live-action, I was doing animation, or photographing animation. So, I was always working frame by frame ... Animators have much more choice in terms of style of movement. (Bokanowski, 1995b: 00'12")

Bokanowski utilizes animation techniques to facilitate a gradual change in the images, capturing unreal movement that is more in keeping with animation. He brings about the idea of simultaneous spaces based on loops perpendicular to the screen, consciously manipulating time and the spatiotemporal rhythm of the animated film.

All these features are reminiscent of experimental animation in the 1920s and 1930s by Walter Ruttman and Len Lye, respectively. They set out a discourse that can be seen as closely aligned with Bokanowski's sensibility - especially in the two animation works analysed in this article - in terms of the fluidity of movement and the synthesis and freedom of experimental forms in motion. These are used by Bokanowski in his image processing and frame-by-frame filmmaking, an approach which does not place a priority on conventional narrative parameters. One of the strengths of experimental animation is that it revisits its principles in favour of inventing a moving expression that diverges from its objectivity. Experimental animation is sometimes conflated with image processing and frame-by-frame techniques in avant-garde cinema, the basis of which lies in free use of cinematic expression. This process of exploring film structures breathes new life into cinematographic language, pursuing a mix of ideological aesthetics. 
Bokanowski's experimentation achieves a type of unseen and distinctive imagery that sits between figurative and abstract art in motion; it alludes to a dreamlike realm and shows the viewer how it changes over time. It can thus be seen how animation allows him to alter visible reality in his films. Bokanowski is one of the greatest auteurs of his generation in French cinema, a symbol of the modern cinema that arose at the start of the 1960s, yet it is difficult to pinpoint which category he belongs to. The personal aspect of his cinema connects with one of the key characteristics of modernism: the absolute subjectivity of the camera as well as the contribution of the individual. The gaze starts inside the subject before opening out to a plural view.

Against this backdrop, Suzanne Buchan (2013) makes a fundamental contribution in Pervasive Animation. Making the case for a recognition of animation as set apart from the dominant models, Buchan states that: 'We hope to stimulate much-needed dialogue and new perspectives centred on the pervasive and multidisciplinary nature of animation' (p. 9). Indeed, the belief is that it is vital to question and break away from the established norms in animation and step outside the traditional track. Thus, this study shows that it is precisely by transcending categories in favour of individual adventures and the personal needs and languages of each filmmaker that the knowledge of animation can be expanded and enriched. Furthermore, the expression of animation can intensify under other, more independent criteria, where less conventional animation can emerge.

Hence, this article seeks to explore the poetic possibilities of the use of unusual reflections in film and animation, basing its analyses on the strategies employed by Bokanowski. These ideas about Bokanowski's use of reflection and mirrors will be specifically linked to his experimentation in film and the subsequent reconstruction of the material using frame-by-frame animation techniques. Taking into account the uniqueness of his films' aesthetics, it is worth noting that, unlike scientific contributions, works of art and/or artistic expressions are characterized by their singularity; in other words, their capacity to stand out as individual works. This is particularly evident in the films that are the subject of this study, providing examples in the fields of artistic cinema and animation.

In addition, this study centres on Bokanowski's aesthetics and the way he extrapolates the pictorial and visual components of a film to achieve greater expressive potential. Moreover, an analysis of these aesthetics will focus on two of Bokanowski's short films: La Plage (1992) and Au bord du lac (1994). The reason why these two titles have been selected is because the images are captured through reflections in mirrors and combined with animation processes to convey a sense of subjectivity. The advances made by Bokanowski in his research into optical systems are taken up and consolidated in these two films. In so doing, he introduces other variables and innovations in his methods, going further still with the deformation resulting from the physical qualities of the mirrors which he marked with dents and localized curvatures, placed according to the landscape to be filmed. This causes transformations in the image projected onto these irregular surfaces. Prior to La Plage, he had not used this technique in the making of any of his films. This handcrafted mirror system, which augments the expressive possibilities of movement, had only previously been used by Bokanowski on a test basis in some photographs, ${ }^{2}$ specifically in 1988 (see Figure 1).

This breakthrough triggered the start of filming La Plage, later culminating in Au bord du lac. A thematic and aesthetic shift occurs in his work by directly filming via mirrors and glass, unlike in his earlier films and even his later work. ${ }^{3}$ As such, both animated films have become exemplars of this methodology.

In the course of Bokanowski's career as a filmmaker, the aforementioned short films mark a turning point in his use of catoptric techniques. The method in question consists of directly capturing the reflected landscape, figures and objects, through a system of sculpted metal mirrors and unstable reflective surfaces, rather than projecting the filmed images onto the reflective surfaces later. The aim is to explore the pictorial qualities of mutation and metamorphosis, endowing the 


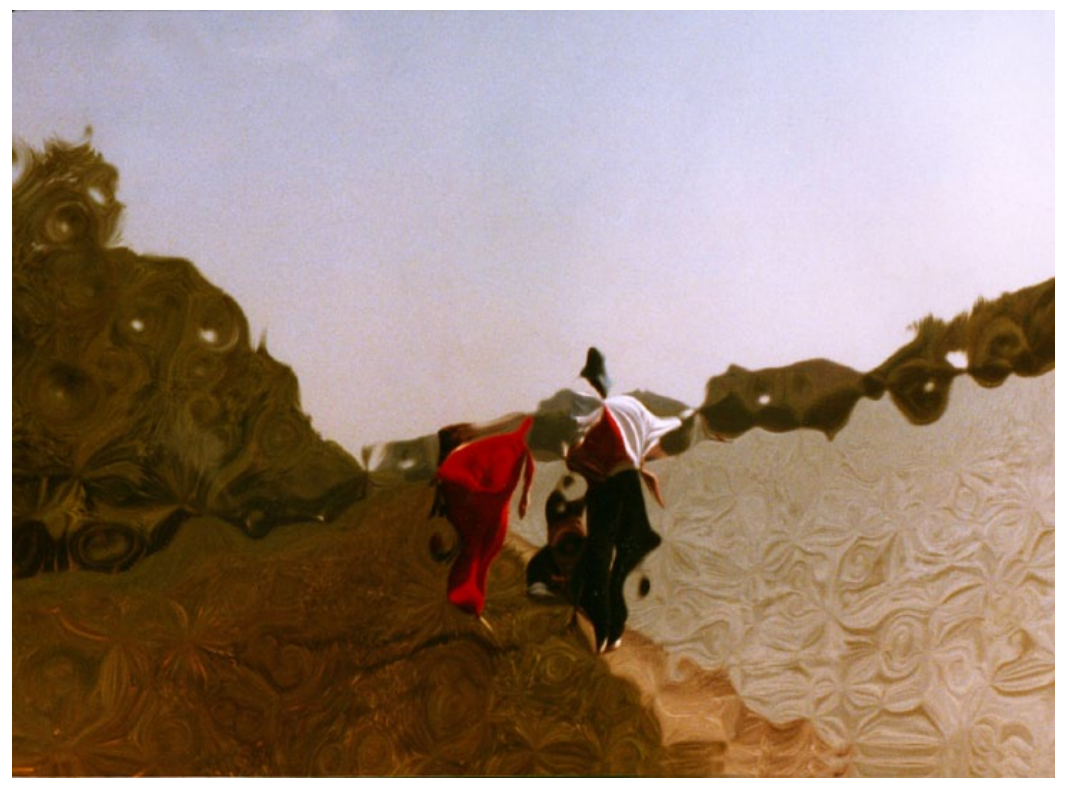

Figure I. Patrick Bokanowski: Photographic test with the mirrors that Bokanowski used for La Plage (1992) and Au bord du lac (1994). (C) photo Patrick Bokanowski. Reproduced with permission.

language with a greater fluidity and malleability due to the vibratory, undulating nature of the reflective surfaces and the unceasing transformation of the images.

By filming the reflections of the environment through liquid mercury, glass, spherical lenses containing imperfections and handcrafted mirrors, Bokanowski is able to alter perceptions and offer different, more subjective perspectives of the natural scenery. He thus evokes his imaginary universe. These short films mark the culmination of his exploration of optical phenomena, where the emphasis is entirely on psychological optical systems.

\section{Patrick Bokanowski (Algiers, 1943)}

Bokanowski is an independent filmmaker primarily known for his 1982 cult film L'Ange. This part-animated work is also considered a ground-breaking contemporary film and is an inspirational reference point for masters of animation such as the Quay Brothers. ${ }^{4}$ Bokanowski's films delve into optical and visual themes, relating to the sensitivity of celluloid and the materiality of the film medium. His works are characterized by re-filming and the use of animation techniques to achieve transformations. His recent remarkable film Un Rêve Solaire (2016) - his second feature-length film - integrates hand-drawn animation sequences subsequently treated with solarization and scenes shot with a Super 8. His latest films are L'Envol (2018) and L'Indomptable (2018).

He studied optics, photography and chemistry in the workshop of the painter Henri Dimier between 1962 and 1966. Apart from his films, he produces drawings, paintings and photographs, as well as installations such as the unnamed one he made in collaboration with Christophe Cardoen, commonly known as Pitch, which was presented at Le Fresnoy, National Studio for Contemporary Arts, as part of the 1997 exhibition Projections, les transports de l'image curated by Dominique Païni. In that installation, Cardoen appears covered with a sheet and is confused with a puppet and a ghost (Païni, 1997: 206). 


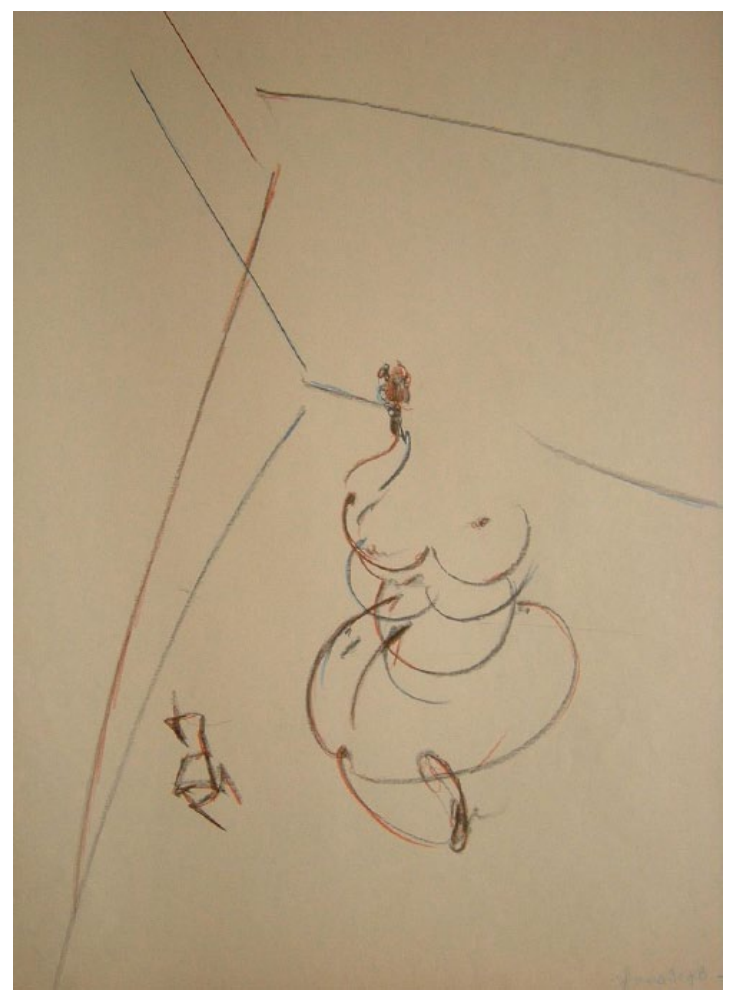

Figure 2. Patrick Bokanowski's 'YF' drawing. Coloured pencils on paper, series from 1988 to 1992 . ( ) photo Patrick Bokanowski. Reproduced with permission.

\section{A mind's eye vision of space-time}

As part of Bokanowski's artistic practice, he utilizes the closed-eye drawing method (which he refers to as 'YF' from the French, Yeux Fermés) in parallel to his film-making, relinquishing the sense of sight when drawing is a tactic that heightens the understanding of space and time from a mental-vision perspective. Through this procedure, the right hemisphere of the brain is activated and this change can be seen in the way in which the drawing, however skilfully or clumsily executed, gains clarity and conviction.

This closed-eye creative strategy resonates significantly in the making of La Plage. In this and other films, Bokanowski completely disengages from any expected relationship with the external and the most superficial aspect of the referent. In this disconnected relationship resides the methodology of the so-called 'YF' drawings, which influences the director during the editing of his films to reshape movement from an inner vision (see Figures 2 and 3).

In an interview with Jayne Pilling, which was later released by the British Animation Awards, he explains this technique:

There's a series of drawings I call YF, which is French for eyes closed. This technique means when I start, I don't look at what I'm doing, I try and imagine a form. I shut my eyes and reproduce this imaginary form. I used to do drawings which were imaginary but with a conventional, classical sense of space. But drawing with my eyes closed, I achieved some surprising results. Gradually, it changed my way of thinking and the 


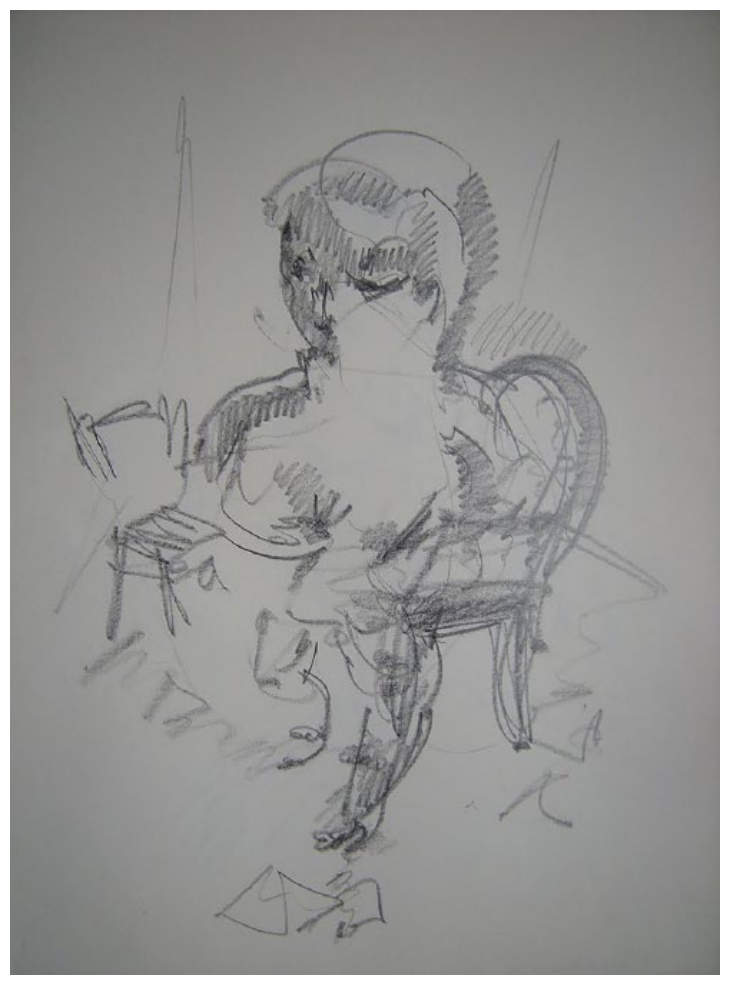

Figure 3. Patrick Bokanowski's 'YF' drawing produced with the closed-eye technique. Graphite pencil on paper, series from 1988 to 1992 . ( photo Patrick Bokanowski. Reproduced with permission.

way I dealt with spatial construction. So, because of these drawings, which I did every day, I learned to look at things in a really different way. (Bokanowski, 1995a: 00'21”)

Bokanowski clarifies how drawing with his eyes closed has produced a remarkable shift in his way of looking below the visible surface of things; this technique has transformed the way he envisages space, generating a different, more inward-looking kind of vision. Bokanowski's inward gaze as a moving spectator provides him with a more extensive, essential image, thanks to its multifocal nature.

Likewise, this technique heightens the other senses. William Wees (1992) makes a very significant point regarding this kind of vision, in his book Light Moving in Time. He writes: "cclosed-eye vision" is not limited to "abstract" patterns of grainy light and colour. It may include the clear, recognizable images of hypnagogia, which emerge full blown yet seemingly unsummoned from the depths of consciousness' (p. 94). Wees reveals a key aspect of closed-eye vision: it transcends shapes because it is bound to emotion and arises from the far reaches of our cognitive experience. In fact, he argues that there are multiple ways of seeing, which contribute to subversive aesthetic languages of avant-garde cinema. These ways of seeing enhance the directors' subjectivity, generating personal visions that do not neatly fit with the retinal forms of viewing associated with a more standard kind of cinema.

Within other forms of less focused viewing, Wees (1992) pinpoints this experience of closed-eye vision or vision in a dark room, which causes visual 'noise', graininess, textures, hallucinations, phosphenes and hypnagogic images. Wees explains that hypnagogia is understood as a perceptual experience associated with the transitional time between wakefulness and falling asleep, or some 
other situation in which people visualize images that do not come from using their eyes to observe an external reality.

This also links to Stan Brakhage's (2004) concept of the 'hypnagogic vision' in the production of moving images; in other words, the vision that emerges beneath the surface of the eye upon closing one's eyes, in an intermediate state between what one feels and what one sees on the inside. According to Brakhage: 5

[Viewers] can shut their eyes and not look at my film, and they can see it going on in their own heads at the same time anyway. It's called hypnogogic vision. All people have in their closed eyes a world of spots, of shapes and forms, of colours, that are all making a piece of visual music. Now, I hope to make it more inspiring, so they're even more inspired by their own particular personal vision. (p. 77)

Like Brakhage, Bokanowski conceives his films as adventures in perception; they involve a search for new horizons of film exploration aimed at stimulating alternative understandings of space through its distortion. In particular, Bokanowski's subjective vision and personal expression of his work in animation are closely attuned to his inner feelings, a harmony that enables him to develop his unique visual style in animation. Indeed, animation affords Bokanowski greater possibilities than other mediums, since the frame-by-frame re-filming allows him more creative control over the artistic process, offering us seemingly real images that are in fact pure invention. Thus, his visual style results in a type of synthesized animated effect that differs radically from outward reality, calling into question conventional perspectival space. The aesthetic outcome suggests a curved space made up of underlying layers corresponding to interior states.

\section{Reflected subjective space}

Bokanowski utilizes mirrors to offer us his internal perspective of space, expressed through the deformation of its constituent elements and the beings who inhabit it. In the selected animated films, these mirrors create a disconnection between objective reality and its representation, exposing his subjective view of that reality. This study, therefore, will not deal with the traditional vision of the mimetic mirror, but rather Bokanowski's particular use of mirrors for their dynamic, intangible, virtual and distorting qualities. In other words, it focuses on their capacity to generate vortices in the images: for example, with reverberations like optical echoes, which are produced by positioning one mirror in front of another to create a mise-en-abyme, or the intentional blurring that can be achieved with certain reflective surfaces. In this way, his works become less transparent, but the evocative capacity of the moving image is intensified. Therefore, Bokanowski does not examine the pure reflectivity of the mirror but rather a kind of diffuse reflection that lends the images a veiled character. In so doing, he inverts their meaning, principally through reflection on mirrors with irregular surfaces, and the refraction of the images in water and lenses. Along with these effects, Bokanowski makes use of the phenomenon of reverberation - both luminescent and acoustic - and incorporates it into his films, generating visual noise and a graininess that amplify the depth and texture of the surrounding spaces. ${ }^{6}$ These are mobile reverberations because the reflected waves collide and radiate out as optic vibrations in concentric waves, the image eroding with psychological resonances. This series of optical phenomena come together to create the perception of heterogeneous spaces, related to Michel Foucault's deliberations in Of Other Spaces: Utopias and Heterotopias. ${ }^{7}$ The philosopher describes a virtualization and a deepening of the gaze towards the other side of the mirror. Foucault argues that:

The mirror is, after all, a utopia, since it is a placeless place. In the mirror, I see myself there, where I am not, in an unreal, virtual space that opens up behind the surface ... But it is also a heterotopia in so far as the mirror does exist in reality, where it exerts a sort of counteraction on the position that I occupy. From 
the standpoint of the mirror I discover my absence from the place where I am since I see myself over there. Starting from this gaze that is, as it were, directed toward me, from the ground of this virtual space that is on the other side of the glass, I come back toward myself; I begin again to direct my eyes toward myself and to reconstitute myself there where I am. (Foucault, 2010[1966]: 70-71)

Foucault's philosophical perspective references the utopian dimension of the mirror, as it opens up another type of 'space' distinct from the tangible, characterized by its immateriality and the illusion of not being anywhere. Hence, the mirror understood in terms of heterotopia creates a visual paradox given the ambivalence between closeness and distance when extending the gaze to the other side of the mirror. In short, it is a contemplation of the mirror as a mechanism for producing virtual images.

The symbolic association of mirrors as counter-spaces is relevant to this discussion of Bokanowski's filmmaking technique and his subjective expression - especially because the process of filming the images for La Plage and Au bord du lac is primarily based on the use of misshapen metallic mirrors and the resulting spatial modifications they produce. The reflective properties of the mirrors flip the position of the objects' images formed with respect to the real axis, virtually duplicating them in another place. That is, they invert the sense of orientation of the space. Due to this visual artistic treatment, the scenes in these films are observed as semi-veiled and deliberately projected onto another, imaginary space opposed to the real one. This world created by Bokanowski is simultaneously perceived as close and far away, where the boundaries of the spaces are out of focus. These landscapes do not have clear contours, instead taking on an almost dreamlike appearance. Interwoven locations transcend the idea of demarcated territory: unlimited spaces on the verge of dissolving, multiplying and expanding. From the outset, this suggests a sense of the re-dimensioning of the immaterial space-time, freeing it from the realist representation: several points of view coexist, everything curves and the dynamic possibilities of the space are expanded.

Bokanowski achieves these sensations by using glass, sculpted mirrors or even capturing the image reflected on fluid mercury. ${ }^{8}$ The latter is conceived of as a liquid mirror producing a kind of silver stream; in certain phases, Bokanowski tries to immobilize it, to enhance the reverberation and capture the internal reflection of the vibration of the space projected onto the mercury. In this respect, a direct reference to Foucault's notion of heterotopia is appropriate, given his description of 'reverberating spaces that reflect one another with discontinuities and breaks' (Foucault, 2010[1966]: 39). This notion overtly incorporates a sense of interconnection between mutually-reflected spaces.

Specifically, in the case of the mirror as a heterotopia, Foucault presents this as a real yet 'virtual' space, which links to the illusionistic qualities of animation. In Bokanowski's animations he manipulates spatial perception, transmuting the logical conception of reality. He does so by means of simultaneity, moving from two to three virtual dimensions articulated in an illusory space. Bokanowski thus lays bare the construction of a cinematic illusion, juxtaposing contrary places with a deliberately denaturalized sense. This crossover produces an ambivalence, which can result in an abstract vision of reality.

The abstract qualities of Bokanowski's imagery, the fundamental features of which are a rich brushstroke effect, vivid colours, a wealth of textures and semi-abstract forms transforming in perpetual metamorphosis, are related to aspects of gesture in paintings in the art of abstract animation. Bokanowski is able to manipulate the form, reassembling it in a non-representative sense, crossing back and forth between real and imaginary worlds in a way that is intrinsic to animation.

Returning to Foucault's (2010[1966]) concept of heterotopia, it is elucidated as a world that comes together with other worlds, creating spatial possibilities that are entirely at odds with conventional ones, as they are expressed through values that are imaginary, sacred or symbolic (p. 25). A feature of these counter-sites is that they go beyond rational logic. The re-dimensioning of a 
real-world space opens up another type of transformable space with traversable elements. These spaces correspond to a non-standard perspective; they are spaces of deviation. At the same time, the fact that they are outside the physical world, alluding to a counter-world, means that they entail a certain degree of subversion and spatial intensity with respect to the dominant structures.

The disparate depths or spatial layers allude to different times, which are interlaced in Bokanowski's works to the point where another type of intangible space arises: the reflected space, corresponding to other orders diverging from reality. In this way, his work transforms our perception of the real space, through psychological optical distortion and animation. Using frame-by-frame animation techniques, he completely reconstructs reality, thereby exploring other rhythmic and spatio-temporal relationships. Moreover, specific techniques such as cut-out and collage animation allow him to create and display this new reality in single-frame animation. Bokanowski transfigures the space, renders it unstable, and makes it more pictorial by means of various textures, stains and abstract, other-worldly forms. Through his distorting mirrors, we hypnotically cross over into the reflected landscape and become absorbed in an atypical, subjective reality. Perceiving his imaginary space entails a process of opening and closing; it is not accessible under ordinary conditions, nor evident at first glance. It projects us into other blurred places and times outside its representative borders. Absorption in the mirror generates a new space in the viewers' perception, which is distended and fluid, with an unfixed location. It dissolves to create a distinct universe, and is reconstructed from a moving vision that assimilates a variety of incompatible perspectives. This immersive sense of space is achieved by bringing together the specific capacities of animation, such as gradual metamorphoses and condensations of the animated forms. By drawing on the qualities of abstraction of the reference landscapes, he manages to recreate them in a non-imitative way.

From the shots filmed in the mirrors, mercury and glass, Bokanowski rebuilds the images frame-by-frame on a modified animation stand in his studio, altering the duration, the changes between frames and mixing a range of techniques to form completely heterogeneous positions; shifting, dissimilar composites that coexist in the same place. For instance, one technique he utilizes is to superimpose acetate sheets on the frame, painting certain areas so that they endow the image with a more graphic feel. He also merges various backgrounds in an attempt to move even further away from a naturalistic or mimetic image of the landscape, towards the lure of spaces that are freed from traditional perspectives. A scene is thus created that is independent of the real action, an inversion, allowing him to suggest another intangible space or imaginary world.

According to Bokanowski (2017a):

The wide variety of styles utilised in animated films is an indication of the possibilities offered by the liberation of the photographic image ... Animation often finds inspiration in 'realistic' forms of cinema - there's no reason why the flow of inspiration shouldn't also operate in reverse ... What kind of processes can we use, to obtain images which remain legible, while possessing a considerable power of suggestion? (pp. 4-5)

The discussion of how the reverse of the space stands in opposition to the real space highlights the capacity of animation to construct other possible orders through alternative spatial logic, as well as its ability to subvert the realist representation of images in order to convey an independent meaning.

\section{Exploring new perspectives: The subjectivity of the camera}

Bokanowski's films focus on close surroundings, but his perspective is less predictable and less mundane than the usual viewpoint. To this end, he invents his own specular distortions that go beyond mere appearance. For this reason, he interprets everyday life in light of what he wants to 
express, intentionally distorting it using sculpted lenses and a combination of mirrors that stimulate individual perception, giving rise to opportunities for expression that go far beyond the reaches of conventional optics. Bokanowski (1992) explains the principle behind creating such markedly different images:

One rejects the iron rule of lenses constructed according to conventional laws of optics, in order to move towards the use of 'subjectives', which allow photographic images to have the same freedom as drawn or painted images. (p. 37, emphasis in original)

As we can see, Bokanowski refers to the camera focus as subjective(s), in a play on the French word for lens: objectif. This wordplay provides an important angle for examining his chosen production method, as it refers to the rhetoric concerning the creation of non-standard images. He is responding to an intrinsic need to rid these images of clichés, in order to free them from the supposed photographic objectivity. His methodology and animation techniques allow him to alter the order of the objectifiable reality and shape his cinematographic language.

Therefore, as a sign of his rejection of the pre-established formulae based on mere trompe-l'ail style imitation, which lead to the standardization and trivialization of images, some of the alternative strategies that he puts forward are founded on exploring fresh new perspectives (tied to knowledge) and envisaging the objective lens of the camera in a very personal and intimate way. Bokanowski always asserts the notion that the camera lens, which he terms 'subjective', is neither neutral nor passive.

Consequently, when making these films, he endeavours to construct his own optical systems using various techniques ranging from the manipulation of small pieces of polished glass (using them like filters) or warped sculpted lenses that are more flexible and more diverse than the prefabricated ones. These intensify the departure from 'reality', which also implies a technical freedom in film production, given that the filmmaker chooses a less technical, more unusual method. In Bokanowski's own words:

The idea was to avoid the kind of lenses sold in stores. I tried to find all sorts of lenses - small, big, medium. They all have what lens makers would call defects and aberrations. But it's precisely that which interested me. (Bokanowski, 2017b: 10'09")

The handcrafted blown glass of his optical devices produces more versatile results, while the new, different shapes of these alternative lenses open up a wide-ranging expressive potential for motion, suggestive of a greater malleability of form. Likewise, it evokes mise-en-abyme, or an infinity mirror effect, like the visual echo that occurs when two mirrors are placed parallel to one another, with the image appearing as an ever-more tenuous repetition of itself in seemingly endless movement.

Bokanowski's films expose the constituent components of the film material, as he rediscovers the connection between the material elements used and the idea that he wants to express in his work. He thus explores the diverse characteristics of the film stock, such as the permeability of celluloid, distortion, porosity and the eventual cracks that draw attention to the virtuality of what is being represented. The film $A u$ bord $d u$ lac provides a notable example of this unique language in the visual metamorphoses created using a series of perforations and the deterioration of the image caused by the effect of the reflection in curved mirrors.

In pictorial terms, the use of these sculpted lenses, combined with other reflective surfaces, produces a kind of mobile reverberation and modified optical properties. A sensory experience of the reality is created, full of textures and nuances that are not merely visual. This technique also has the ability to enrich the unique character of the subject; indeed, one of the interesting aspects of 
Bokanowski's work is that it transforms the everyday into something extraordinary. Thus, the visual style of his animation fully unleashes the fantasy: a non-literal interpretation of the world that facilitates the poetics of animation.

\section{The catoptric method in animation}

In the two animations analysed in this article, Bokanowski applies the catoptric method to evoke his subjective view of space-time. This system (from the Greek for mirror, katoptron), which is primarily based on mirrors as well as other reflective surfaces, involves a set of optical processes that affect the properties of the reflected light, determining the optical deviation of the object in relation to the formation of the images and the physiology of vision. Bokanowski develops such a system in his film work, especially in the short films La Plage and Au bord du lac, shooting with mirrors located outside the camera for the initial capture. He explains:

The inspiration here was, I really like the Italian painter Francesco Guardi, 17th century. His figures are always painted as if with vibrating lines. After all the work I did with Dimier, I wanted to create figures or a street, or nature, or any scene - so that they vibrate. Watching these images move in the mercury and realizing that only certain distortions really struck me as interesting and suggestive, I wanted to be able to fix the mercury in place. That's when I moved on to another method. I began to recreate the mercury's undulations on stainless steel sheets. I'd hammer the sheets to inflict specific impact marks, which could transform the image in a way similar to waves, etc. (Bokanowski, 2017b: 21'06”)

Based on the method of filming images on the oscillations of liquid mercury, Bokanowski goes on to re-create this procedure on metal mirror plates. He specifically employs a wide variety of mirrors, each measuring $65 \mathrm{~cm}$ x $80 \mathrm{~cm}$ x $3 \mathrm{~mm}$. He makes preliminary studies of 200 metallic mirrors, from which he selects 20 to use in these films. In particular, Bokanowski plays with stainless steel mirror plates as they allow him to make impacts on the physical surfaces and have more control over the material. To do so, he calculates all the mathematically possible deformations and he makes impacts with special hammers, reproducing the undulations in a more accurate way, in specific areas depending on the object to be filmed. He thus prepares the localized transformations of the landscape for La Plage and Au bord du lac.

First, Bokanowski makes a series of sketches of the size of the impact on the mirror. He then adds markings to the back of the mirror to identify where the impact should go and the corresponding deformation, before finally making the physical impacts on the metal using the special hammers. This method yields a malleable quality that fosters a shift in the forms, caused by the richness and diversity of the impacts and the variety of textures and modulations on the physical surfaces (Chodorov, 2017: 23'30"). The marks on these reflective surfaces substantially affect the images reflected in them because they send back reflected spaces that are completely dissimilar from the external world, with their own individual texture caused by the physical qualities of the dents.

Similarly, the lenses he uses to capture the images in the two films mentioned above are pieces of semi-transparent, hand-blown glass. These pieces of glass are placed in front of the object to be filmed (at a minimum distance of $1 \mathrm{~mm}$ from the object being filmed), and they are moved to the left or right. ${ }^{9}$

This approach underlines the significance of Bokanowski's animated imagery, opening up new, independent paths in animation by exploring materials, searching for his own language and shaping alternative strategies centred on the distinctiveness of the animated process. In this regard, Halas and Manvell in Art in Movement: New Directions in Animation (1970) claim that: 
Animation, although a small part of the total structure of the film industry, is a medium which is creating new ideas and styles, and seeking out-of-the-way forms to a far greater extent than other forms of filmmaking or the living theatre. Because of its flexibility of technique, and the fact that the artist is still in full control through his individual contact with the medium, it is a more immediate form in which to carry out creative experiment. Since the creation of motion - whether achieved through frame-by-frame-progression, camera mobility, or the manipulation of light effects - is the essence of animation, it is the pure form of art which comes closest to the kinetic movement. (p. 12)

The authors point out the suitability of animation as a medium for experimentation. The importance is thus clear of the need to develop other visual methods and experimental approaches, opening the door to different avenues to explore in animation.

Furthermore, Halas and Manvell highlight certain fundamental aspects of animation that can facilitate such experimentation: movement is achieved through complete control of the image by means of frame-by-frame processing, linked to its kinetic possibilities, and always involves a consideration of the spacing between frames. Indeed, Bokanowski takes advantage of this complete control of the image to create a stylized vision of reality. Through the use of frame-by-frame animation, time elapses in a precise measured tempo in his animated films, with a gradually intensifying kinetic rhythm.

Other aspects, such as the mobility of the camera in animation, offer possibilities of changing the viewpoint. The camera can be positioned in ways that would not be possible with live action. This is particularly notable in Bokanowski's animated films, which rely on tilting, panning and other camera movements that give rise to unusual points of view in order to recreate curved spaces. He also utilizes changes in the light in single-frame animation as a fundamental feature of his animated work.

\section{Catoptric method: Case study}

La Plage (1992) (colour, I 4 min, France). This short film is structured around a poetic vision of several seaside scenes, and it takes place during the intervals between darkness, from dawn to sunset (see Figure 4). The film is broken down into four parts, based on kinetic rhythms and space-time vibration. The leitmotif of the work is the expression of the passing of time, the fusion and metamorphosis of the elements, and the transitory identity of the bodies and forms; this is achieved by imposing cyclical changes of light.

The calming rippling movement of the waves moved by the wind slowly intensifies. It starts with a gradual change from localized to widespread movement until the theme transforms. This does not happen linearly, however, given that the sea in the closing scene once again takes on a slower and more recognizable rhythm, like the first part of the film, but at the opposite end of the chromatic scale.

Also, as this work develops, it undergoes a metamorphosis, a qualitative mutation. This primarily occurs in the third part with the introduction of action, as the characters sail out to sea. The image fluctuates between a kind of erosion and aggradation, forming an organic whole. At times, this vacillation between the two creates a sensation of spatial ambiguity, an amorphous quality that affects both the viewer's perception of the shapes and the film's production of meaning. The growing movement of the waves accompanies the imaginary transformation of the characters, ultimately generating a visual palimpsest of colours and aggradations that appear to intensify in certain sequences. With it, the evanescent figures become almost unrecognizable (see Figure 5).

This film sheds light on the changing essence of nature through the fusion of various different experiences on the beach between the sun and the waves. The figures blend with their surroundings, their edges disappear and they melt into a universal whole. 


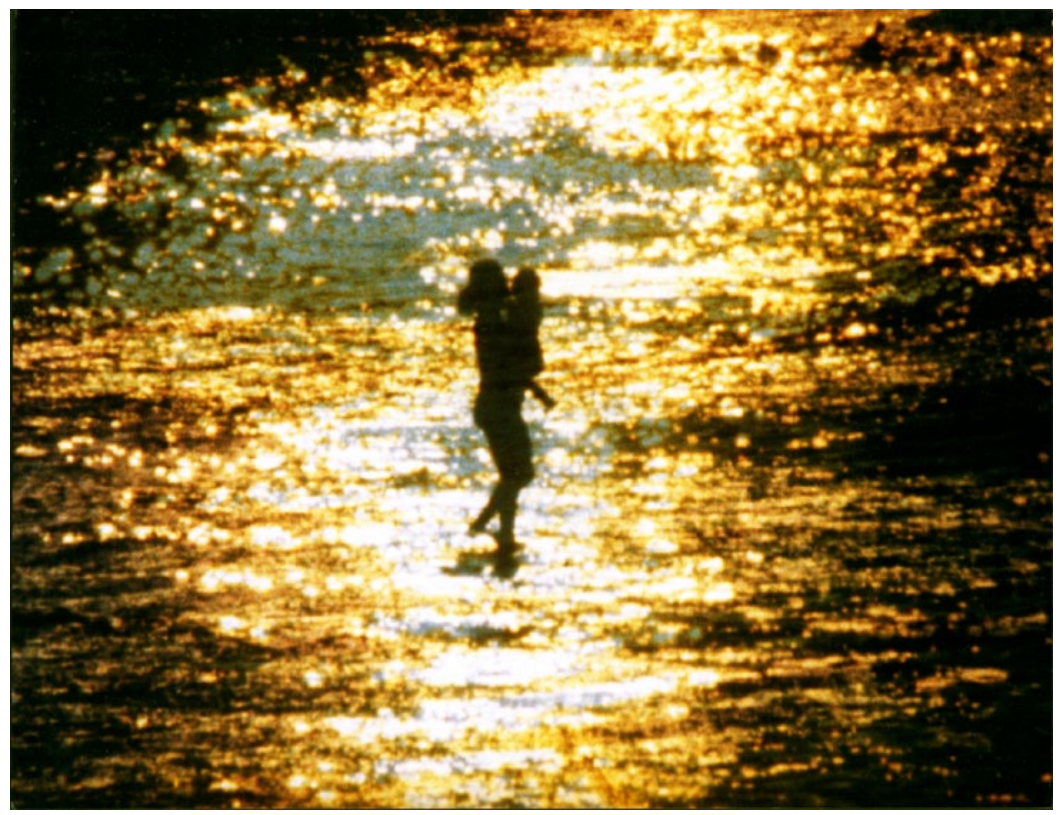

Figure 4. Patrick Bokanowski. Frame, still photo. From the fourth part of La Plage (1992). ( photo Patrick Bokanowski. Reproduced with permission.

\section{Film technique: Images captured on mirrors and re-filmed with animation in the third part of La Plage I (1992)}

A fade to black leads us from the second to the third part of the film, followed by a defined cut made by a light greyish frame appearing with the number three in black in the centre of the image. After this frame, the image brings us back to the sea where the action is taking place. In this section, however, there is a shift in the mood: it is now broad daylight, the activity begins to ramp up and there is greater interaction between the living beings and nature.

A number of visual changes to the language are introduced and revealed. From an overarching long shot of the beach, which characterizes the final sequences of the second part of the film, we move to a long shot at the start of the third part. The rhythm is slow and vibratory, with delayed shots of a pictorial nature. The slowing down of the shots reinforces a certain air of suspense. In this first segment, we become aware of the reduced pace, which Bokanowski achieves by using an animation camera to re-film from the real film, altering the time by re-shooting frame-by-frame and incorporating the change between frames (see Figure 6, 6'03" and Figure 7, 5'02')

An analysis of the first segment of the third part reveals a succession of shots of an intimate and psychological nature. In the first shot of the third part, the characters, expressed in a semi-abstract way, are submerged in the water, bathing in the sea. The setting is dynamic, as can be seen in the incorporation of the diagonals in the compositions. The action takes place in the water, where the bathers are in deeper than in the previous parts (1 and 2). In this segment, there is a radical shift away from a naturalistic aspect and we start to see a series of formal alterations in the images. These are produced in a very distinctive way, through intense optical distortion techniques. They suggest haptic experiences and allude to the moving quality of the beach later on in the day, the great vitality of the beach in summer, thus transmitting a sense of joyous fullness. 


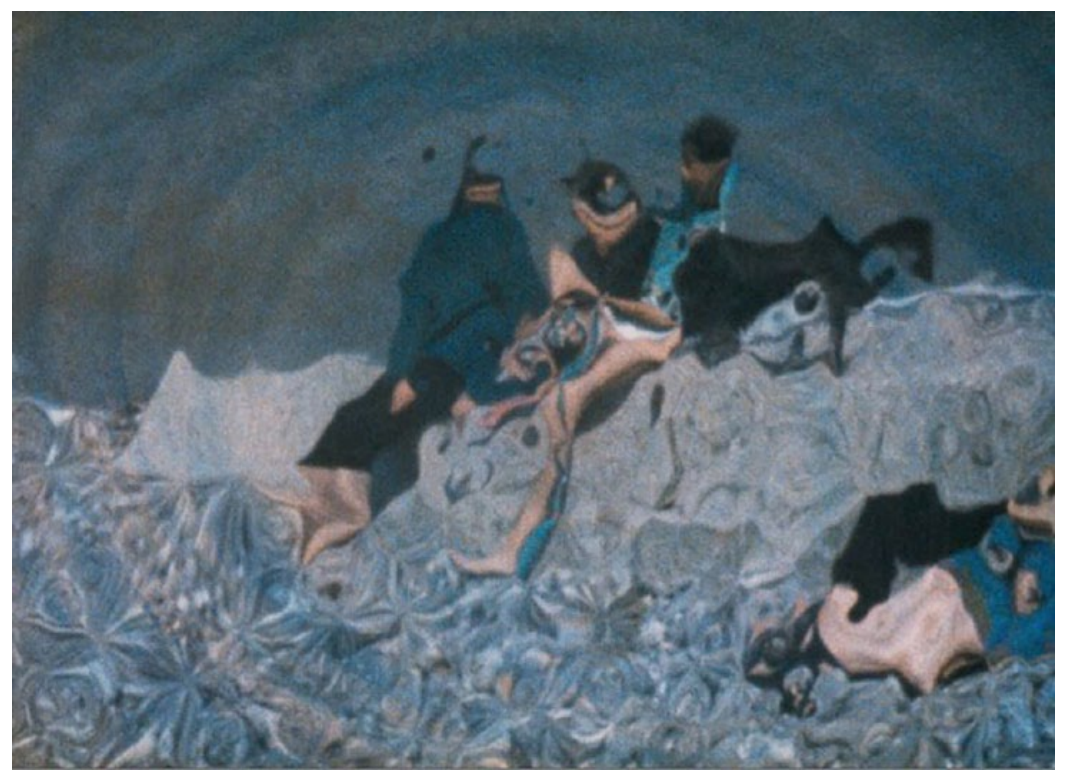

Figure 5. Patrick Bokanowski. Frame from the third part of La Plage (1992). () photo Patrick Bokanowski. Reproduced with permission.

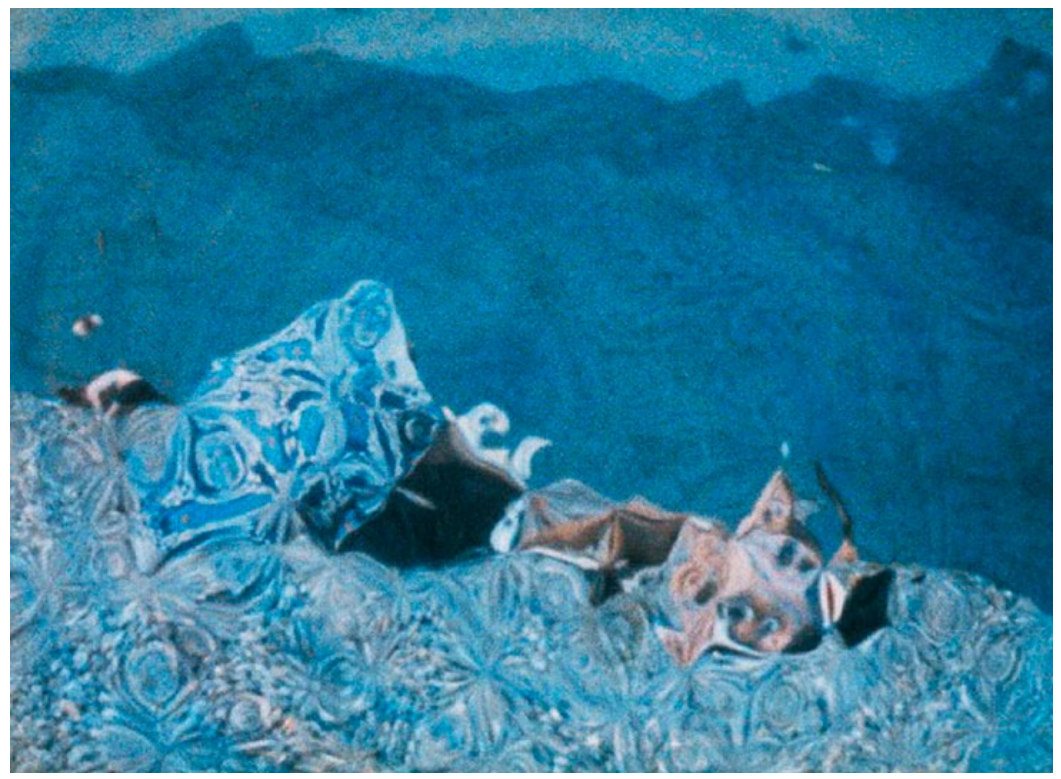

Figure 6. Patrick Bokanowski. Frame, still photo. Third part of La Plage (1992). @ photo Patrick Bokanowski. Reproduced with permission.

This third part is filled with long outdoor shots, combined with medium-long shots to more fully draw us into the action. They reveal a variety of characters woven into the background, latent within the landscape. These figures become more closely intertwined due to the increased intensity 


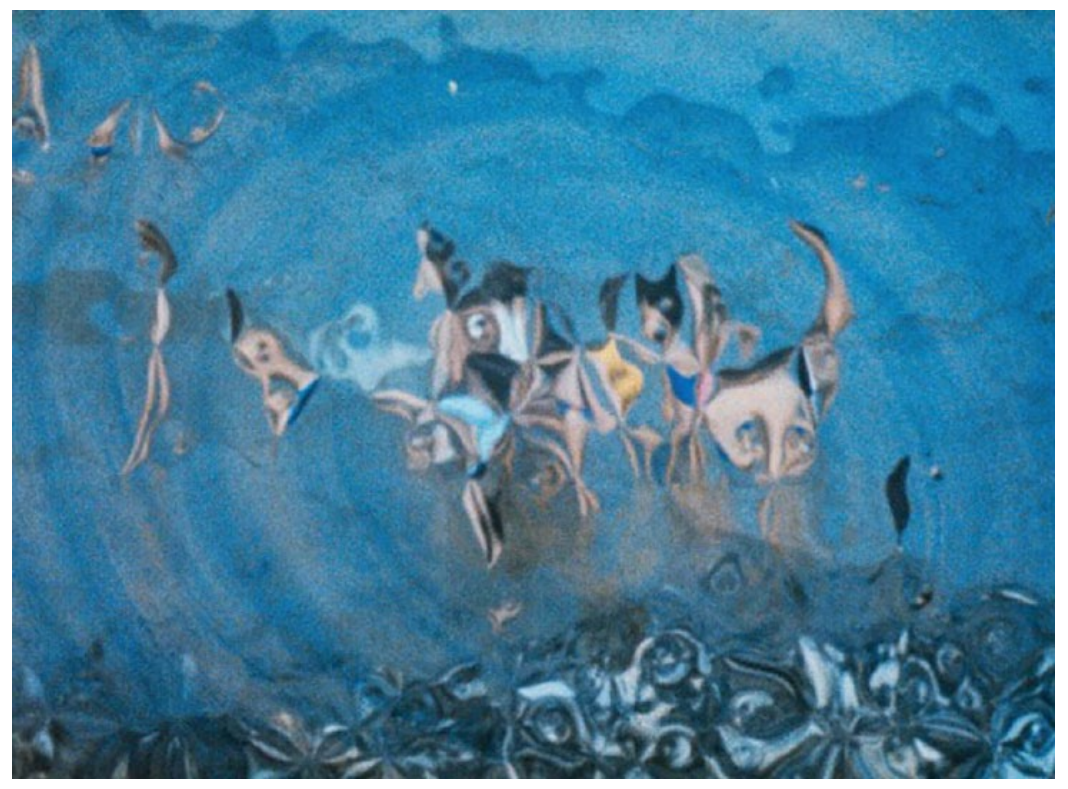

Figure 7. Patrick Bokanowski. Frame, still photo. Third part of La Plage (1992). Image filmed through mirrors and glass. (C) photo Patrick Bokanowski. Reproduced with permission.

in aspects such as the chromatic contrast, the porous texture, the tilt and the change in size of the elements. In the first segment of the third part, the shrouded characters are observed closer to the camera, despite the enigmatic presence of the twisted, obscured figures that are discovered in transition between frames. However, the glass, oscillating slightly in front of the subject being filmed, is manipulated by moving it away from or bringing it closer to the object, figure or landscape to be filmed. In addition, the irregular semi-reflective mirrors that distort the image being filmed directly on them allow the physiognomy of the objects to remain unidentified; instead, these objects form part of the environment, fusing with the background and maintaining a type of veil in the image.

The glass, sculpted lenses and mirrors bestow an appearance of fine mists and sinuosities that help keep the figures semi-hidden, blended or wrapped in a halo of mystery. In this sense, there is a tension between the limit of the visible, where the forms that appear are at the point of disappearing. The distance is deliberate: an attempt to achieve another type of intermittent perception of the figures, which heightens the enigma surrounding them and their vibration in the space.

Likewise, another key element worth noting in this part of the film is the progressively greater artistic transformations, endowing the landscape with a feel of moving paint and with a highly personal graphic language in each of the frames. This is reinforced by the layer-by-layer reconstruction, and the graphic overlay of different painted areas of frames. All of this is done under the camera, interleaving transparent tracing papers into spaces between the material previously filmed directly on the metal mirrors, the sculpted lenses and the handcrafted glass.

These customized lenses were situated outside the camera from the first shot, shaping the optical distortion in the original capture of the image. For the production of the third part of La Plage, these lenses offer a malleable and spectral quality to the images reflected. Thus, in this part of the film, the forms are subverted, breaking away from realistic features and taking on an autonomy in the film, producing a sublime effect of unreality. In this segment, the sifting, semi-diffuse light prevents us from seeing the limits of the space and, therefore, the great visual repercussion becomes evident. 
In order to achieve this effect, Bokanowski uses two sources of distortion. First, there is the projection onto metallic mirrors hammered with a series of localized impacts, which are very different from one another in terms of their reflective surfaces, causing a wide range of internal distortions covering the width of the frame of the third part. These mirrors are outside the camera and affect the original recorded image from the first shot of La Plage.

The second source of distortion is Bokanowski's exploration of filming through oval or circular glass, which is perceptible in the reflected marks of the concentric, elliptical waves and the spirals laid down in the formation of the transferred image. For instance, this can be seen in the foreground of the first third of the image, where the reflected images possess traces of these moving, irregular, semi-transparent and translucent media (see Figures 6 and 7), alluding to the changing conditions of the movement of the waves. The result is a hybridization of the transitioning forms that diffuse into the sea, where the landscape seen on the screen becomes amorphous, sensorially softer and more humid. This is a more daring way of capturing the immediacy of open forms.

A more granular and uneven image emerges, producing more intensity and creating sensations of vertigo within the beach, generated by a series of hypnotic spirals. These seemingly endless curves foster a sense of expanding space and a spinning sensation, creating a set of undulating rhythms and vibrations, which are at the same time caused by the reflections that wrap the figures in a serpentine trail of spirals, vortices, a proliferation of waves and concentric reflections. As the action progresses, these combine to form an organic array of fluid masses.

It should be noted that this animated 'movement' is not built up through successive phases of the action; the transformation is self-generated with sculpted lenses and dented mirrors. This endows the sequence with dynamism and instability, a disregard for the external aspect, an elongation and compression of the figures and exaggerated perspectives, all of which also contribute to amplifying the tension and the unsettling nature of the film.

\section{Au bord du lac (1994) (colour, 6 min., France)}

This short film set at the edge of a lake focuses on metamorphosis. The images in $A u$ bord du lac are captured on different mirrors, prisms of water, glass or liquid mercury of varying densities and moving at differing speeds. The director produces suggestive images by filming the reflected images when the mercury is oscillating gently, or in certain phases he captures more stirring images, for example by immobilizing the liquid, as mentioned above.

Next, he examines and re-films the projected images in the moving reflections of the lake with an animation camera, breaking down the movement and using animation to impose more substantial transformations. Bokanowski is thus able to manipulate the image, ensuring that the viewer perceives the formation or disintegration of the animated forms. In this film, the identity of the characters cannot be clearly made out at first glance; then the view becomes sharper, and only through transition are we able to pull back this illusory veil and grasp the essence of the characters in movement, who can be perceived as part of the background in a kind of symbiosis.

Furthermore, the film examines and implies a certain ambivalence between the figure and the background, which are continually swapped around. Space plays a central role, almost like a figure in certain still images, and with the slightest movement between frames, the optical illusion of the undefined figure fleetingly appears then disappears again, inverting the perception between positive and negative space. This interaction gives rise to a multistable perception of reversible figures, which accommodates more than one possible meaning. 
Au bord du lac not only reveals the displacement of the figures in space but the altered environment also melts into the movement. The turmoil between figure and background is articulated in an integrated whole. The sensation is one of seeing things from within the specular water, which produces an enveloping effect through the reverberation.

\section{Conclusions}

We believe that the title of this article is an apt synthesis of Bokanowski's ideology; he does not display an overt reality, but rather veils and unveils spatial resonances that are mutated by means of a transparent layer, creating mystery and sustaining a sense of intrigue as he shares his subjective vision with us. Bokanowski expands the physical landscape's boundaries, revealing a manysided composition with a noticeable hypnotic quality. In the resulting image, sensations of sight, sound and touch are interwoven to evoke a synaesthetic perception in the viewer. Starting from this pictorial conception of space-time, he transforms and re-animates the material obtained from his surroundings, using animation to draw us into the domain of constantly evolving semi-abstract imagery. His reconstruction of the image creates a profound vision that penetrates and unravels in its own universe, revealing the deep layers of the artistic elements in his animation.

Our analysis of two of Bokanowski's highly influential short films and the groundbreaking techniques he uses in these works highlights the rich variety of approaches in contemporary animation. His pioneering method of filming on handcrafted mirrors, which create transformations in the reflected images and facilitate the expression of movement, has helped awaken a creative re-imagining of animation.

The innovation in Bokanowski's application of catoptric systems consists of the transgression of aesthetics and narrative in animation and experimental cinema, enabling subjective transformation of the image and articulately emphasizing the state of transition between the images. By experimenting with an array of different optical phenomena, Bokanowski has given rise to a novel transmutation of the language, opening up new avenues for animation research.

\section{Acknowledgements}

We express our sincerest gratitude to Patrick Bokanowski for providing us with the frames and photographs of the drawings from his collection and allowing us to publish them in this article. We also thank him for having responded to our questions. In addition, we are grateful to Dr Rogério Taveira for referring us to several initial bibliographical sources and to Emma Porritt for her support given with the translation.

\section{Declaration of conflicting interests}

The authors declare that there is no conflict of interest.

\section{Funding}

The authors disclosed receipt of the following financial support for the research, authorship, and/or publication of this article. This work was supported by the Spanish Ministry of Economy, Industry and Competitiveness, and was co-financed by the European Social Fund in the call for applications for Predoctoral Scholarships for Doctoral Training: [BES 2014-069330], within the framework of the R\&D\&I project: Alternative Strategies for the Creation of Animated Images Based on Its Essence: The Dynamic Expression [HAR2013-41708-P].

\section{Notes}

1. See Suzanne Buchan's (2006) discussion about the term 'world' in an animation context, in her Introduction to Animated 'Worlds', initially presented at a conference in 2013 at Farnham Castle, England. 
2. For more information, see the interview with Patrick Bokanowski in the documentary film Visite à l'atelier by Pip Chodorov (2017, France), for example, minute 22'34".

3. This aesthetic, generated by distorting mirrors, is taken up again in Bokanowski's films such as L'Envol (2018) and L'Indomptable (2018), albeit in an allegorical way by means of digitally 'deformed reflections', unlike the shooting and construction of the images through real physical mirrors in the short films La Plage and Au bord du lac.

4. Along with David Lynch, Patrick Bokanowski is one of the contemporary film directors to have had a significant influence on the films of the Quay Brothers. See: https://www.austinchronicle.com/ screens/2015-09-18/the-brothers-quay/

5. Brakhage made this point in his interview with Bruce Kawin at the University of Colorado Boulder in 2000.

6. Reverberation is the prolonged emission of a diffuse reflection.

7. Foucault's heterotopias originally formed the basis of a lecture given to the Cercle d'études architecturales, France: AMC Arquitecture, mouvement, continuité in 1966.

8. These techniques will be detailed in the section 'The catoptric method in animation'.

9. See Visite à l'atelier (Pip Chodorov, 2017), the documentary film about Bokanowski released by Re:Voir, Paris, for instance, minute 11'11'”.

\section{References}

Bokanowski P (1982) Patrick Bokanowski: L'Ange. France, remastered for the British Animation Awards DVD, 2009. London: Kira BM Films.

Bokanowski P (1992) Réflexions Optiques. Paris: In Bref, n.11, 34-38.

Bokanowski P (1995a) 'Eyes Closed' Drawings. In: Patrick Bokanowski's Short Films, France. Bonus features: Interview with Patrick Bokanowski by Jayne Pilling, remastered for the British Animation Awards DVD, 2009. London: Kira BM Films.

Bokanowski P (1995b) Working Frame by Frame. In: Patrick Bokanowski's Short Films, France. DVD. Bonus material: Interview by Jayne Pilling, remastered for the British Animation Awards DVD, 2009. London: Kira BM Films.

Bokanowski P (2009) Patrick Bokanowski's Short Films. France. Remastered for the British Animation Awards DVD. London: Kira BM Films.

Bokanowski P (2017a) Incandescent Material, Notes on the Cinematic Image. Published in booklet included in: Un Reve Solaire DVD 2018. Paris: Re:Voir, 3-7.

Bokanowski P (2017b) Interview with Patrick Bokanowski. In: Short films by Patrick Bokanowski. DVD Bonus features. Remastered for Re:Voir, DVD 2018. Paris. Re:Voir.

Bokanowski P (2018) Court-métrages: Patrick Bokanowski. Remastered for Re:Voir Video DVD. Paris: Kira BM Films.

Brakhage S (2004) Stan Brakhage. Madrid: Museo Nacional Centro de Arte Reina Sofía - Arts Centre Publishing.

Buchan S (2006) Introduction. In: Buchan S et al. (eds) Animated 'Worlds. London: John Libbey, vii-xii.

Buchan S (2013) Pervasive animation: An introduction. In: Buchan S et al. (eds) Pervasive Animation. New York: AFI Films Readers/Routledge, 1-21.

Chodorov P (2017) Visite à l'atelier. France. In: Short Films by Patrick Bokanowski, 2018. DVD Bonus material. Paris: Re-Voir.

Foucault M (2010[1966]) The Utopian Body: Heterotopias. Buenos Aires: New Vision.

Halas J and Manvell R (1970) Art in Movement: New Directions in Animation. London: Studio Vista.

Ishaghpour Y (1986) De derrière le miroir. In: Cinéma Contemporain de ce Côté du Miroir. Paris: La Différence, 318-331.

Païni D (1997) Projections, les Transports de l'Image. Tourcoing-Paris: Hazan-Le Fresnoy-AFAA.

Wees W (1992) Light Moving in Time: Studies in the Visual Aesthetics of Avant-Garde Film. Berkeley: University of California Press.

Wells P (1998) Understanding Animation. London: Routledge. 


\section{Author biographies}

Tamara Rama is a Research Technician at the Polytechnic University of Valencia (UPV) Spain, specialising in the Arts. She is also a member of the Department of Drawing's Artistic Expression through Movement: Animation and Lumino-Kinetics Group at the UPV. She holds a Degree in Fine Arts and a Master's in Artistic Production from the Polytechnic University of Valencia. Her final Master's thesis dealt with artistic animation and experimental cinema, and the present dissertation is essentially derived from the research undertaken while writing her doctoral thesis Moving Image Projected Onto the Mirror: Alternative Supports for Projecting Movement. She collaborates in teaching assignments at the Faculty of Fine Arts of Valencia at UPV.

Carmen Lloret holds a Professorship in Movement and Animation at the Polytechnic University of Valencia (UPV), Spain, and a Doctorate of Fine Arts (1985). She heads the UPV's Plastic Arts Expression of Movement: Animation and Lumino-Kinetics Research Group, where her fundamental aim is theoretical research into the plastic expression of movement. She is a multidisciplinary artist and animated film creator. She has mounted 145 exhibitions in Portugal, Chile, England, Switzerland, Mexico, Taiwan and Spain, and been awarded 45 prizes for her work in Plastic Arts and Animation. She has directed 5 R\&D projects, supervised 18 doctoral theses, and has published over 30 articles. A Professor of Movement and Animation since 1976, she has coordinated the Doctorate Programme in Animation at both the UPV and the IPL in Portugal since 1999.

Address: as Tamara Rama.

Email: taraso@bbaa.upv.es 